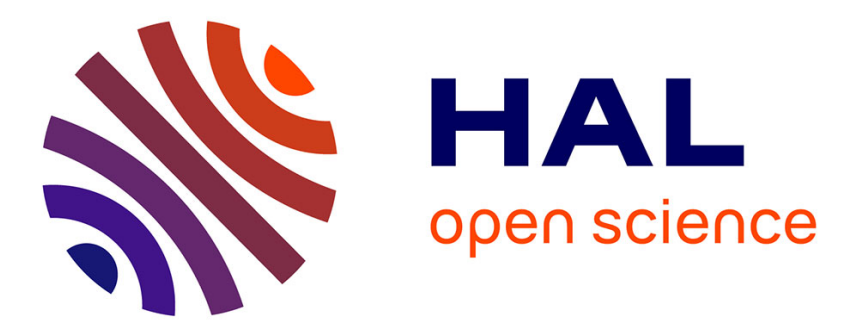

\title{
Energy transfer from Fe3+ to rare-earth ions in YAG and the problem of sensitization of laser emission
}

\author{
V. Lupei, A. Lupei, S. Bonea, M. Nanau, M. Bolog
}

\section{To cite this version:}

V. Lupei, A. Lupei, S. Bonea, M. Nanau, M. Bolog. Energy transfer from Fe3+ to rare-earth ions in YAG and the problem of sensitization of laser emission. Journal de Physique IV Proceedings, 1994, 04 (C4), pp.C4-505-C4-508. 10.1051/jp4:19944121 . jpa-00252572

\section{HAL Id: jpa-00252572 https://hal.science/jpa-00252572}

Submitted on 1 Jan 1994

HAL is a multi-disciplinary open access archive for the deposit and dissemination of scientific research documents, whether they are published or not. The documents may come from teaching and research institutions in France or abroad, or from public or private research centers.
L'archive ouverte pluridisciplinaire HAL, est destinée au dépôt et à la diffusion de documents scientifiques de niveau recherche, publiés ou non, émanant des établissements d'enseignement et de recherche français ou étrangers, des laboratoires publics ou privés. 


\title{
Energy transfer from $\mathrm{Fe}^{3+}$ to rare-earth ions in YAG and the problem of sensitization of laser emission
}

\author{
V. LUPEI, A. LUPEI, S. BONEA, M.P. NANAU and M. BOLOG \\ Institute of Atomic Physics, Bucharest 76900, Romania
}

\begin{abstract}
The static and dynamic measurements of $\mathrm{Tm}^{3+}$ spectra in YAG:Fe:Tm show that the ${ }^{3} \mathrm{H}_{4}$ level is efficiently populated by transfer from $\mathrm{Fe}^{3+}$ in tetrahedral sites. The features of the transfer processes, by investigation of $\mathrm{Tm}^{3+}$ acceptor luminescence characteristics, are presented.

The two micron $\mathrm{Tm}^{3+}$ laser emission is hampered by the low absorption of the radiation from the existing sources. To overcome this difficulty, the co-doping with transition metal ions has been used, $\mathrm{Cr}^{3+}$ ion being the most used sensitizer.

The possibility of sensitization of $\mathrm{Tm}^{3+}{ }^{3} \mathrm{H}_{4}$ luminescence in YAG by co-doping with $\mathrm{Fe}^{3+}$ was already demonstrated $[1,2]$. The energy transfer involves $\mathrm{Fe}^{3+}$ in d-tetrahedral sites, whose emission from ${ }^{4} \mathrm{~T}_{1}\left({ }^{4} \mathrm{G}\right)$ level has a good superposition with ${ }^{3} \mathrm{H}_{4} \mathrm{Tm}^{3+}$ multiplet absorption in this matrix, especially at elevated temperatures.

Our previous studies concern mainly the static and dynamics spectral characteristics of the donor, $\mathrm{Fe}^{3+}$ (d), in the YAG:Fe:Tm samples. The data show clearly two features: (i) a complex behaviour of the global $\mathrm{Fe}^{3+}$ (d) luminescence decay under non selective pumping. It depends on $\mathrm{Tm}^{3+}$ content and at long times after the laser pulse could be described by a Forster law, indicating a dipole-dipole energy transfer mechanism with a temperature increasing $\mathrm{C}_{\mathrm{DA}}$ micro-parameter. This interaction could not describe the beginning of the decay suggesting stronger interactions between near neighbours Fe-Tm pairs; (ii) the presence of new satellite lines in $\mathrm{Fe}^{3+}$ (d) absorption spectra (near the sharp line corresponding to ${ }^{6} \mathrm{~A}_{1} \rightarrow{ }^{4} \mathrm{~T}_{2}\left({ }^{4} \mathrm{D}\right)$ transition) and a complete quenching of the donor $\mathrm{Fe}^{3+}(\mathrm{d})$ emission at pumping in these absorption peaks. These satellites could be assigned to $\mathrm{Fe}^{3+}$ (d)-Tm (c-dodecahedral) near neighbour pairs. The transfer within these pairs is very efficient. The YAG structure allows several types of close $\mathrm{Tm}^{3+}$ (c) $-\mathrm{Fe}^{3+}$ (d) pairs. Thus, near an $\mathrm{Y}^{3+}$ c-site there are two $\mathrm{Al}^{3+}$ d-sites at $3 \AA$, four at $3.67 \AA$, eight at $5.16 \AA$ etc. The presence of pairs and the almost $100 \%$ transfer efficiency within them might be taken into account in the analysis of $\mathrm{Fe}^{3+}$ sensitizations of $\mathrm{Tm}^{3+}$ emission.

Since $\mathrm{Tm}^{3+}$ acceptor luminescence lines are much sharper, the satellite structure induced by $\mathrm{Fe}^{3+}$ co-doping is more complex and can provide additional information on the energy transfer processes. The aim of this paper is to present new data on $\mathrm{Tm}^{3+}$ spectra in YAG:Fe:Tm samples. Single crystals of YAG:Fe, YAG:Tm, and YAG:Fe:Tm, with various concentrations up to $5 \%$ have been comparatively investigated.
\end{abstract}


The absorption spectra (10K) of co-doped YAG:Fe:Tm samples present a complex satellite structure around $\mathrm{Tm}^{3+}$ main lines. Besides the lines observed in YAG: $\mathrm{Tm}^{3+}$ samples (line $\mathrm{N}$ corresponding to unperturbed $\mathrm{Tm}^{3+}$ centers and $\mathrm{P}$-lines from centers perturbed by non-stoichiometric defects) [3], up to three new satellites $F_{i}$ have been detected in various $\mathrm{Tm}^{3+}$ transitions, as illustrated in Fig. la for the ${ }^{3} \mathrm{H}_{6}\left(\mathrm{Z}_{1}\right) \rightarrow{ }^{3} \mathrm{H}_{4}\left(\mathrm{~W}_{1}\right)$ transition of a YAG:Fe(5\%): $\mathrm{Tm}(5 \%)$ sample. The intensity of $\mathrm{F}_{\mathrm{i}}$ lines increases with dopants content, but due to the overlapping with P-lines and to their relative low intensity, a concentration dependence is difficult to measure.

When the $\mathrm{Tm}^{3+}$ emission is activated by the transfer from $\mathrm{Fe}^{3+}$, at short times after the laser pulse the ${ }^{3} \mathrm{H}_{4}$ luminescence is dominated by the three $F_{i}$ centers emission, as illustrated in Fig. 1b for a YAG:Fe(1\%):Tm(1\%) sample, excited non selectively with $532 \mathrm{~nm}$. This effect is more pregnant at high $\mathrm{Tm}^{3+}$ concentrations.

The luminescence decays of various $F_{i}$ centers are similar, but very different from that of the main line $\mathrm{N}$; a clear rise time being observed in the later case. The rise time is concentration and temperature dependent. The ${ }^{3} \mathrm{H}_{4}$ luminescence decays for $\mathrm{N}$ (Fig. 2a) and $F_{1}$ (Fig. 2b) centers for a YAG:Fe(1\%):Tm(1\%) sample at $10 \mathrm{~K}$ are presented in Fig. 2 . The lack of any rise time for $\mathrm{F}_{\mathrm{i}}$ emission indicate a very efficient transfer from $\mathrm{Fe}^{3+}(\mathrm{d})$ to $\mathrm{Tm}^{3+}$.

The $\mathrm{F}_{i}{ }^{3} \mathrm{H}_{4}$ emission could be also observed by selective excitation with a dve laser in the corresponding lines of the $\mathrm{Tm}^{3+}{ }^{3} \mathrm{~F}_{3}$ multiplet. This way one can obtain a better selectivity and some specific characteristics of $F_{i}$ spectra could be observed. One feature must be outlined: $F_{i}$ spectra contain more lines than $N$ spectra. For illustration, in Fig. 3 we present part of the $\mathrm{Tm}^{3+}{ }^{3} \mathrm{H}_{4} \rightarrow{ }^{3} \mathrm{H}_{6}$ emission for $\mathrm{N}$ and $\mathrm{F}_{\mathrm{i}}$ centers at $10 \mathrm{~K}$ obtained by selective pumping in ${ }^{3} F_{3}$ multiplet. If the $F_{3}$ emission is similar to that of $N, F_{1}$ and $F_{2}$ present new intense lines. Their presence can be correlated with structural data. For $D_{2}$ group, the local symmetry at the normal c-sites occupied preferentially by $\operatorname{Tm}^{3+}$, the $\Gamma_{i} \rightarrow \Gamma_{i}$ transitions are forbidden. The presence of intense lines such as those corresponding to $W_{1}(\Gamma$ $\left.{ }_{1}\right) \rightarrow Z_{2}\left(\Gamma_{1}\right)$ for $F_{1}$ and $F_{2}$ centers indicate a strong perturbation of the crystal field and a lowering of the local symmetry at $\mathrm{Tm}$ c-site induced by a near neighbour $\mathrm{Fe}^{3+}$ ion. These perturbations could alter all the transition probabilities for these centers.

Thus the static and dynamic luminescence measurements show that the ${ }^{3} \mathrm{H}_{4}$ level of $\mathrm{Tm}^{3+}$ could be very efficiently populated by energy transfer from $\mathrm{Fe}^{3+}$ ions in tetrahedral sites. The ${ }^{3} \mathrm{H}_{4}$ level populates ${ }^{3} \mathrm{~F}_{4}$ laser level the by the known cross-relaxation process $\left({ }^{3} \mathrm{H}_{4}\right.$, $\left.{ }^{3} \mathrm{H}_{6}\right) \rightarrow\left({ }^{3} \mathrm{~F}_{4},{ }^{3} \mathrm{~F}_{4}\right)$; the efficiency of this process could be reduced to some extent by a possible chain of transfers ${ }^{3} \mathrm{H}_{4} \mathrm{Tm} \rightarrow \mathrm{Fe}^{3+}$ (a) $\rightarrow{ }^{3} \mathrm{H}_{5} \mathrm{Tm}$, ending again in ${ }^{3} \mathrm{~F}_{4}$. Two possible losses could be introduced here by the presence of iron: excited state absorbtion from ${ }^{4} \mathrm{~T}_{1}\left({ }^{4} \mathrm{G}\right)$ to ${ }^{4} \mathrm{~T}_{2}\left({ }^{4} \mathrm{G}\right)$ of $\mathrm{Fe}^{3+}$ and ground state absorbtion ${ }^{5} \mathrm{E} \rightarrow{ }^{5} \mathrm{~T}_{2}$ in $\mathrm{Fe}^{2+}$. Our measurements show that while ESA in $\mathrm{Fe}^{3+}$ peaks at higher energies than the main $\mathrm{Tm}^{3+}{ }^{3} \mathrm{~F}_{4}$ emission, GSA of $\mathrm{Fe}^{2+}$ is centered on this emission. Therefore, extreme care should be taken in the crystal growth to avoid the formation of $\mathrm{Fe}^{2+}$. 


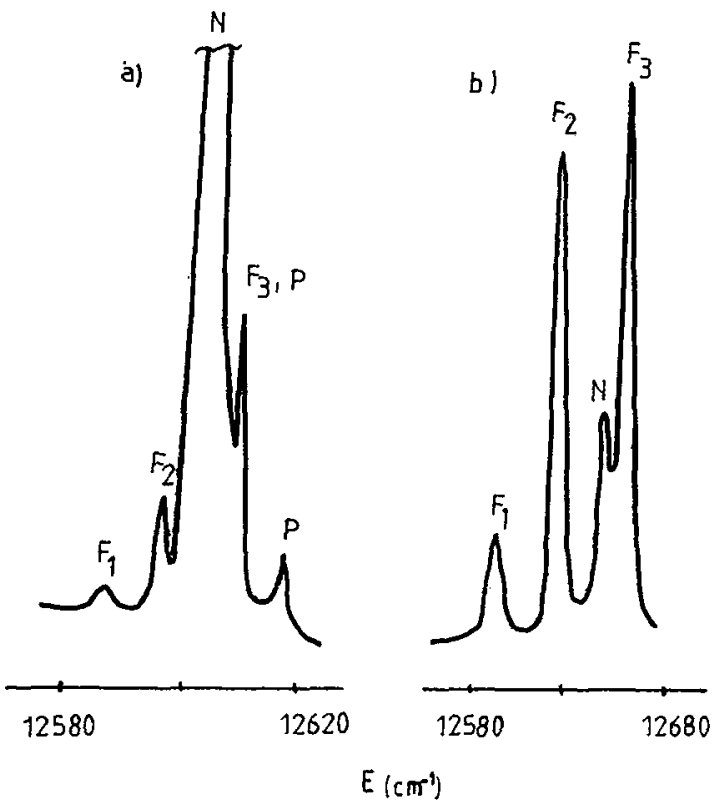

Fig.1.a). Absorption spectum of a YAG:Fe(5\%)Tm(5\%) sample at $10 \mathrm{~K}$; b) ${ }^{3} \mathrm{H}_{4}$ emission for a $\mathrm{YAG}: \mathrm{Fe}(1 \%) \mathrm{Tm}(1 \%)$ sample.

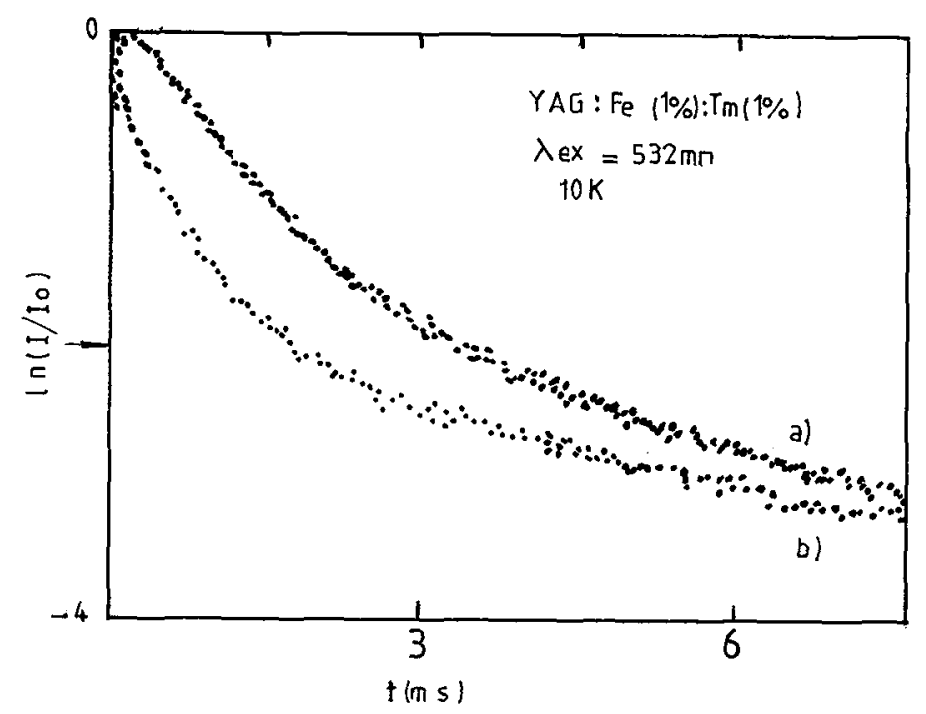

Fig.2. ${ }^{3} \mathrm{H}_{4}$ luminescence decay for: a). the main line $\mathrm{N}$; b). $F_{1}$ satellite. 

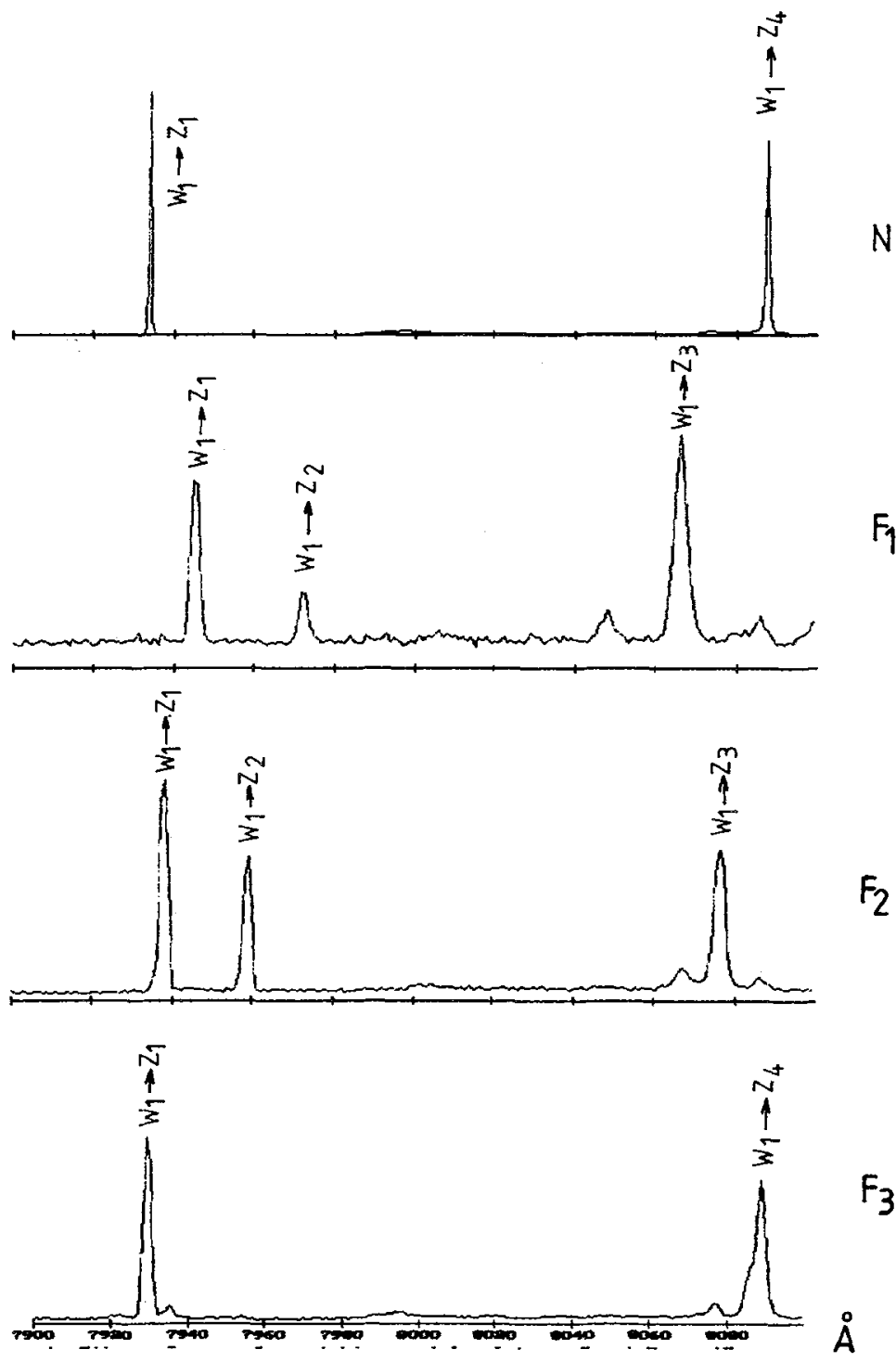

Fig. 3. Part of the $\dot{H}_{4}$ emission of $N$ and $F_{i}$ centers in a YAG:Fe(1\%) Tm(1\%) sample at selective excitation in ${ }^{3} F_{\hat{j}}$.

References

1. V. Lupei, G. Boulon, A. Brenier, C. Madej, M.J. Elejable, A. Lupei, C.Tiseanu, and S.Georgescu, Solid State Lasers IV QE/Laser'93, (Proceed. SPIE).

2. V. Lupei, G. Boulon, M.J. Elejable, A. Brenier, and C. Perdini, Phys. ReV $B$, (to be published).

3. A. Lupei, C. Tiseanu, and V. Lupei, Phys. Rev. B 47, 14084 (1993). 